\title{
inu \\ Motivation and Productivity of Employees in Higher Education during the First Lockdown
}

\author{
Jacqueline R. Rietveld *, Djoerd Hiemstra, Aleid E. Brouwer and Jan Waalkens
}

Academy International Business Administration and Human Resource Management, NHL Stenden University of Applied Sciences, 8917 DD Leeuwarden, The Netherlands; Djoerd.hiemstra@nhlstenden.com (D.H.); aleid.brouwer@nhlstenden.com (A.E.B.); jan.waalkens@nhlstenden.com (J.W.)

* Correspondence: jacqueline.rietveld@nhlstenden.com

check for updates

Citation: Rietveld, Jacqueline R., Djoerd Hiemstra, Aleid E. Brouwer, and Jan Waalkens. 2022. Motivation and Productivity of Employees in Higher Education during the First Lockdown. Administrative Sciences 12: 1. https://doi.org/10.3390/ admsci12010001

Received: 1 October 2021

Accepted: 5 December 2021

Published: 21 December 2021

Publisher's Note: MDPI stays neutral with regard to jurisdictional claims in published maps and institutional affiliations.

Copyright: (C) 2021 by the authors. Licensee MDPI, Basel, Switzerland. This article is an open access article distributed under the terms and conditions of the Creative Commons Attribution (CC BY) license (https:// creativecommons.org/licenses/by/ $4.0 /)$.

\begin{abstract}
In a cross-sectional study among 623 employees of a higher education institution, we examined the relations between perceived competence, autonomy, relatedness, intrinsic motivation, and productivity during the first lockdown in the spring of 2020. The results indicate that, relative to the period before the lockdown, the employees experienced an increase in autonomy and competence, but a decrease in relatedness, intrinsic motivation, and productivity. Structural equation modelling revealed that the decrease in productivity can be explained by a decrease in intrinsic motivation, which in turn can be explained by changes in relatedness, autonomy, and perceived competence. Thus, during the lockdown, both positive and negative motivational consequences of teleworking were observed. However, the ultimate consequence for employees' productivity was negative. An important difference between this study and previous studies on the topic of teleworking, is that the present examined the motivational process under extreme circumstances in which employees had to switch overnight form onsite to remote working.
\end{abstract}

Keywords: remote work; motivation; productivity

\section{Introduction}

The 'intelligent lockdown', announced in the Netherlands in 2020 to contain the imminent COVID-19 epidemic, offered a unique opportunity to research the consequences of enforced teleworking for employees' motivation and productivity. The lockdown suddenly made working from home mandatory. As from 12 march 2020, enforced teleworking was the reality for about $40 \%$ of the Dutch working population (Statistics Netherlands 2020).

Many studies performed to date have shown positive relations between teleworking, motivation, and productivity (Baane et al. 2011; Koppes et al. 2011; Bae et al. 2019; Sanders and Karmowska 2020). For example, in a survey study performed by Major et al. (2008), 60\% of the employees reported higher productivity after introduction of teleworking schemes. Similar outcomes were found in observational studies (Gajendran et al. 2014), and experimental studies have shown positive effect of teleworking on productivity as well (Bloom et al. 2013; Baruch 2001). However, typically, teleworking is implemented gradually, partly, and voluntarily, whereas during the lockdown teleworking was introduced overnight, for the whole working week, and enforced. Therefore, we do not know whether, under these conditions, we will find similar positive outcomes as in previous studies. To better understand the impact of swift, complete, and enforced implementation of teleworking among employees who typically work on site, we examined the changes in motivation and productivity of employees of a large educational institution in the Netherlands during the lockdown. The insights from this study may help companies, institutions, and authorities to draw up their teleworking policy during the COVID-19 crisis and beyond, and to prepare for a future in which teleworking, no doubt, will play a vital role. 


\subsection{Theoretical Framework: Self-Determination Theory}

The research model that we tested in the present study is shown in Figure 1. The model is based on Ryan and Deci's $(2000,2020)$ seminal work on self-determination theory (SDT). According to this theory, it is not just the degree of motivation (high-low), but also the quality of motivation (intrinsic-extrinsic) that impacts our behaviour. Within this framework, intrinsic motivation is considered an optimal type of motivation. When we are intrinsically motivated, our motivation comes from within, and we engage in a task or activity because it is inherently fulfilling (Legault 2020; Vallerand 1997).

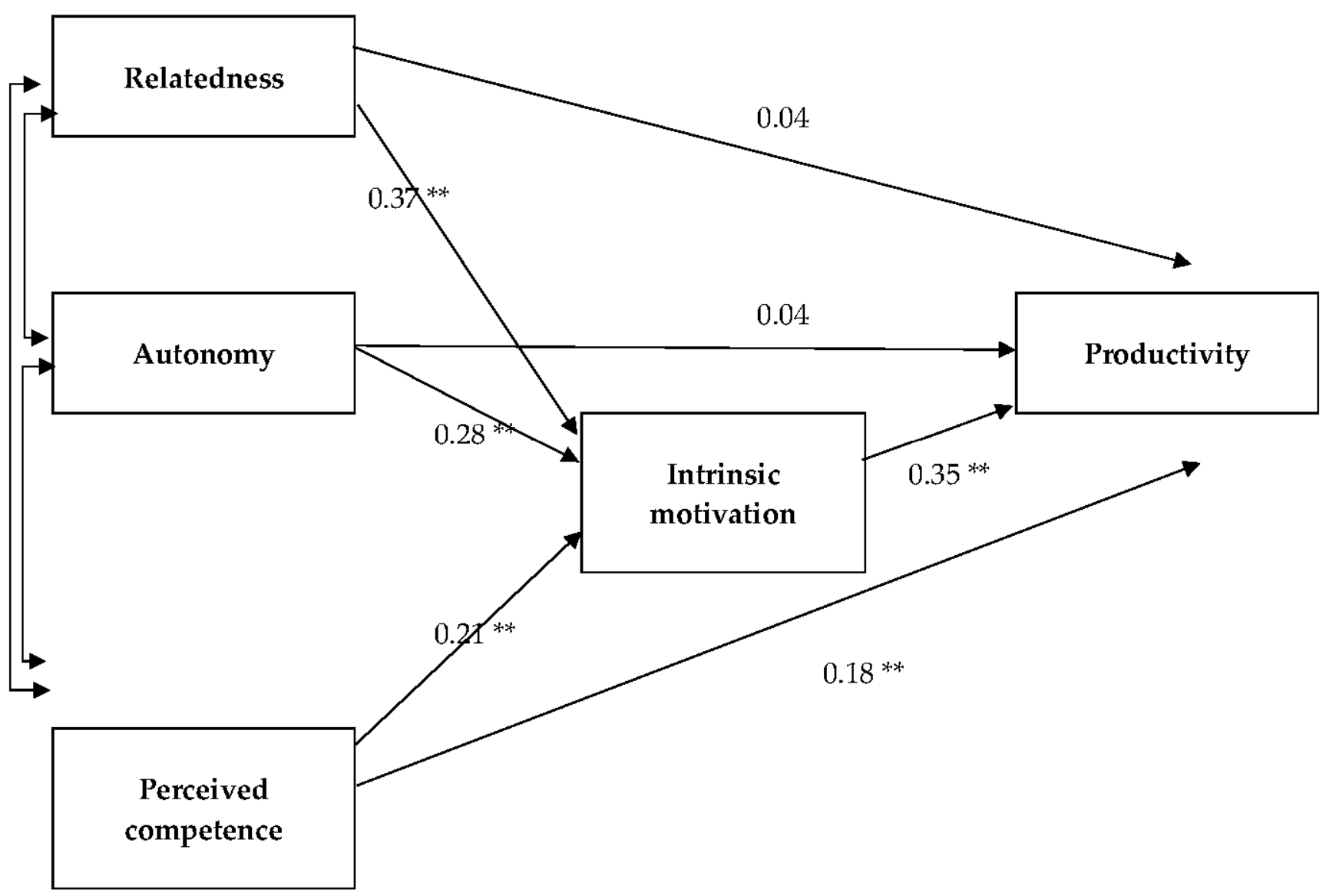

Figure 1. Standardised regression coefficients Model 1. ${ }^{* *} p<0.01$.

Self-determination theory postulates that the degree to which we are intrinsically motivated is determined by the degree to which an activity or situation meets three fundamental human needs: relatedness, autonomy, and perceived competence (Deci and Ryan 2012a). We will be more intrinsically motivated as we experience more connection with others (Dery and Hafermalz 2016), more freedom of choice, and more self-confidence at work. Consequently, we will experience our work as more enjoyable, and we will be more inclined to invest time and energy in it.

Within this framework, in the present study, the key question is, to what extend employees experienced changes in their relatedness, autonomy and competence, and consequently, in their intrinsic motivation and productivity at work during the lockdown.

\subsection{Relatedness during the Lockdown}

To function optimally, it is important for people to have meaningful relationships with others and belong to a group. As such, relatedness is a key source of motivation (Galletta et al. 2011). Ample research supports this view (Deci and Ryan 2012a). For example, in an 
educational context, teachers have been found to be more motivated when they perceived more relatedness with their students (Klassen et al. 2012).

In the context of telework, lack of relatedness has been frequently indicated as a reason for disappointing results. Various researchers have pointed out that teleworking may cause a sense of isolation, which may negatively impact employees' productivity (Hoornweg et al. 2016; Hamersma et al. 2020; Wang et al. 2020; Brynjolfsson et al. 2020). Moreover, employees have appointed the need for personal interaction as an important reason why they prefer working onsite (Delanoeije and Verbruggen 2020).

During the lockdown, employees are likely to miss their social contacts at work. In education, social interaction with students and colleges is a key element of work. Therefore, diminishing the frequency and quality of employees' social interaction will certainly impact their motivation. Thus, we hypothesized that, during the lockdown, employees would report a decrease in relatedness at work.

\subsection{Autonomy during the Lockdown}

When people experience a high degree of freedom of choice and can determine their own goals and working methods, they will get more enjoyment and satisfaction from their work. As such, autonomy is a key source of motivation (Deci and Ryan 2012b). In the context of work, research has repeatedly show positive links between autonomy, intrinsic motivation, and productivity (Galletta et al. 2011).

In the present study, we hypothesized that, during the lockdown, employees would perceive a slight increase in autonomy at work. On the one hand, employees who work from home may experience less supervision and have more freedom to determine their own working hours, activities and working methods (van der Kleij et al. 2013). Indeed, several studies have found positive associations between teleworking and autonomy (Kurland and Cooper 2002; Gajendran and Harrison 2007; Wang et al. 2020). On the other hand, teleworking may entail restrictions on employees' autonomy (Sewell and Taskin 2015). For example, Sewell and Taskin (2015) indicate that teleworkers may experience severe pressure to participate virtually, because they fear to be overlooked when the work is distributed. Also, employees may feel pressured to immediately reply to online messages, since they fear negative judgements if they fail to respond quickly enough. Furthermore, employers' fear of losing control may actually prompt an increase in supervision and control of telework (Errichiello and Pianese 2016; Dambrin 2004).

During the lockdown, teleworking was not a matter of free choice. Employees were forced to work from home overnight. Therefore, we hypothesized that employees would experience only a slight increase in autonomy during the first lockdown.

\subsection{Perceived Competence during the Lockdown}

Individuals' belief that they are equipped for a task plays a crucial role in their motivation. When we believe we can successfully attain our goals, we will be inclined to invest time and money in it. Several theories, including Bandura's (2012) self-efficacy theory and Ryan and Deci's (2020) self-determination theory, have emphasised the crucial role of perceived competence in motivation, and ample research has supported this view (for reviews, see Baumeister et al. 2003).

During the lockdown, employees were taken out of their usual routine. Suddenly, they had to do their work under different circumstances work. They could no longer use all the familiar facilities at the workplace. They had to learn new skills, such as virtual conferencing and online presentation. Employees who are suddenly forced to work under completely different conditions, are likely to feel less competent at work. Thus, we expected that, during the lockdown, employees would experience a decreased level of competence.

\subsection{Intrinsic Motivation and Productivity during the Lockdown}

When we are intrinsically motivated, we perform our work because we enjoy it (Vallerand 1997). That is, we engage ourselves because the activities at work give us 
pleasure and satisfaction, rather than because we expect rewards or punishment from others. Research has shown that intrinsic motivation is associated with a range of favourable outcomes, such as effort and persistence (Reeve 2002), challenge seeking (Vansteenkiste et al. 2004), and performance (Guay et al. 2008).

Self-determination theory (Ryan and Deci 2020) postulates that individuals will be more intrinsically motivated as they perceive more relatedness, autonomy, and competence. As indicated above, we expected that during the lockdown employees would experience a decrease in relatedness and competence, and a slight increase in autonomy. We speculated that the beneficial role of increased autonomy would not compensate for the detrimental role of decreased relatedness and competence (Grant et al. 2013). Hence, we hypothesized that employees would experience a decrease in intrinsic motivation. In line with self-determination theory, we expected that a decrease in intrinsic motivation would be associated with a decrease in productivity.

\subsection{Hypotheses}

The research model that we tested in this study is presented in Figure 1. Our hypotheses were as follows:

Hypothesis 1. During the lockdown, employees experience (a) decreased relatedness, (b) increased autonomy, (c) decreased competence, (d) decreased intrinsic motivation, and (e) decreased productivity.

Hypothesis 2. The relationship between (a) perceived relatedness, (b) autonomy and (c) competence, on the one hand, and productivity, on the other hand, is mediated by intrinsic motivation.

\section{Method}

\subsection{Participants}

Participants in the study were employees of a Dutch higher education institution. In total, $623(36 \%)$ of the 1,751 employees participated in the study, of whom $364(58.5 \%)$ women, $259(41.5 \%)$ men, $386(62 \%)$ teaching staff and $237(38 \%)$ support staff. The average age was $47.2(\mathrm{SD}=11)$. No significant relations between sex or job occupation, and the variables of our research model were found.

\subsection{Procedure}

The data were collected anonymously by means of an online survey that was distributed to all the employees by email. All the participants gave their prior informed consent to participation in the study.

\subsection{Measurements}

All the variables were measured on a three-item scale. The items for relatedness, autonomy, perceived competence, and intrinsic motivation were based on the relevant sub-scales of the Intrinsic Motivation Inventory (IMI; Misbah et al. 2021; Ryan 1982). The original items were translated, and slightly modified for the purpose of this study. For each item, the first part of the statement read: "Compared to a normal working week, prior to the enforced telework situation, ... ". Examples of the second part of the statement are:

- " "... my relatedness to the work ..." (Relatedness),

- " "... the freedom I have to make my own choices at work... " (Autonomy),

- " "... my belief that I am good at my job ... " (Perceived Competence),

- " "... my pleasure at work ..." (Intrinsic Motivation),

- " "... the amount of work I get done ... " (Productivity).

The reply options ranged from 1 (has strongly decreased) to 5 (has strongly increased). The scores for the three items of each variable were averaged to calculate the score for that variable. 


\subsection{Statistical Analyses}

We tested Hypothesis 1 by comparing the average scores on each variable with the score 3 (not decreased/not increased). A significantly higher score than 3 means that the average participant experiences an increase compared to the pre-lockdown period. A significantly lower score than 3 means that the average participant experiences a decrease compared to the pre-lockdown period.

We tested Hypothesis 2 by comparing structural models (SEMs). We started from a model (i.e., Model 1; see Figure 1) with both direct relations (from relatedness, autonomy, perceived competence and intrinsic motivation to productivity) and indirect relations (from relatedness, autonomy and perceived competence via intrinsic motivation to productivity). Subsequently, one by one, we eliminated the least significant relationships from the model (i.e., Model 2 through Model 4). The most austere model that showed an acceptable goodness of fit on the indicators ( $p>0.05$; SRMR $<0.08$; CFI $>0.90$; RMSEA $<0.08$ ) recommended by Kline (2015) was preferred.

\section{Results}

\subsection{Testing Hypothesis 1}

The average scores for the variables, and the corresponding standard deviations, are presented in Table 1. The results indicate a decrease in relatedness, a slight increase in autonomy, a slight increase in perceived competence, a decrease in intrinsic motivation, and a slight decrease in productivity. All scores significantly $(p<0.001)$ deviate from value 3 (no decrease/no increase). Thus, Hypotheses 1a (decreased relatedness), $1 \mathrm{~b}$ (increased autonomy), $1 \mathrm{~d}$ (decreased intrinsic motivation) and 1e (decreased productivity) are supported and Hypothesis 1c (decreased perceived competence) is rejected.

Table 1. Average scores, standard deviations, and correlations $(\mathrm{N}=623)$.

\begin{tabular}{lcccccccc}
\hline & $\boldsymbol{M}$ & SD & Alpha & $\mathbf{1 .}$ & $\mathbf{2 .}$ & $\mathbf{3 .}$ & $\mathbf{4 .}$ & $\mathbf{5 .}$ \\
\hline 1. Relatedness & 2.70 & 0.72 & 0.80 & - & & & & \\
2. Autonomy & 3.07 & 0.69 & 0.82 & $0.15^{* *}$ & - & & & \\
3. Perceived & 3.08 & 0.66 & 0.89 & $0.42^{* *}$ & $0.41^{* *}$ & - & & \\
competence & & & & & & & \\
$\begin{array}{l}\text { 4. Intrinsic } \\
\text { motivation }\end{array}$ & 2.33 & 0.76 & 0.89 & $0.50^{* *}$ & $0.42^{* *}$ & $0.48^{* *}$ & - & \\
5. Productivity & 2.91 & 0.85 & 0.88 & $0.30^{* *}$ & $0.26^{* *}$ & $0.38^{* *}$ & $0.47^{* *}$ & - \\
\hline$* * 0.01$.
\end{tabular}

\subsection{Testing Hypothesis 2}

The correlations between the variables are presented in Table 1 . The results show that all variables are significantly correlated. Figure 1 presents the standardised regression coefficients for Model 1 (i.e., the model with both all direct and all indirect relations). We see a significant direct link between relatedness $(\beta=0.37 ; p<0.001)$, autonomy $(\beta=0.28$; $p<0.001)$ and perceived competence $(\beta=0.21 ; p<0.001)$, on the one hand, and intrinsic motivation, on the other hand. We also see a significant direct link between perceived competence and productivity $(\beta=0.18 ; p<0.001)$. However, the direct link between relatedness and productivity $(\beta=0.04 ; p=0.35)$, and between autonomy and productivity $(\beta=0.04 ; p=0.37)$ is not significant.

To determine the optimal model, we first removed the least significant link (i.e., the link from autonomy to productivity) from Model 1. The fit indicators of the resulting model (Model 2) are presented in Table 2. The results show an acceptable fit with the data $\left(d f=1 ; X^{2}=0.79 ; p=0.37\right.$; SRMR $=0.00 ; C F I=1.00 ;$ RMSEA $\left.=0.00\right)$. Next, we also removed the direct link from relatedness to productivity from the model (Model 3). Model 3 shows slightly better fit indicators $\left(d f=2 ; X^{2}=1.44 ; p=0.49\right.$; $\mathrm{SRMR}=0.00 ; \mathrm{CFI}=1.00$; RMSEA $=0.00)$ relative to Model 2. 
Table 2. Fit indicators of structural models.

\begin{tabular}{lcccccc}
\hline & $d f$ & $X^{\mathbf{2}}$ & $\boldsymbol{p}$. & SRMR & CFI & RMSEA \\
\hline Model 1 & 0 & - & - & 0.00 & 1.00 & 0.34 \\
Model 2 (excl. A $\rightarrow$ PR) & 1 & 0.79 & 0.37 & 0.00 & 1.00 & 0.00 \\
Model 3 (excl. A $\rightarrow$ PR and V $\rightarrow$ PR) & 2 & 1.44 & 0.49 & 0.00 & 1.0 & 0.00 \\
Model 4 (excl. A $\rightarrow$ PR, V $\rightarrow$ PR and & 3 & 26.21 & 0.00 & 0.03 & 0.97 & 0.11 \\
EC $\rightarrow$ PR) & & & & & & \\
\hline
\end{tabular}

Finally, we also removed the direct link between perceived competence and productivity from the model (Model 4). However, this model shows a slightly worse fit ( $d f=3$; $X^{2}=26.21 ; p=0.00 ;$ SRMR $=0.03 ; \mathrm{CFI}=0.97$; RMSEA = 0.11) than the previous model. Hence, we preferred model 3.

The standardised regression coefficients of model 3 are presented in Figure 2. Bootstrapping analyses, based on 5000 re-samples, show a significant indirect effect (a) from relatedness via intrinsic motivation to productivity of 0.17 (95\%BCA-CI $[0.12,0.22], \mathrm{SE}=0.03)$, (b) from autonomy via intrinsic motivation to productivity of 0.13 (95 \%BCA-CI [0.09, 0.18], $\mathrm{SE}=0.02)$ and (c) from perceived competence via intrinsic motivation to productivity of $0.10(95 \% \mathrm{BCA}-\mathrm{CI}[0.06,0.715], \mathrm{SE}=0.03)$. We conclude that the relationship between relatedness, autonomy, and perceived competence, on the one hand, and productivity, on the other, was mediated by intrinsic motivation. However, note that a direct link between perceived competence and productivity was observer as well.

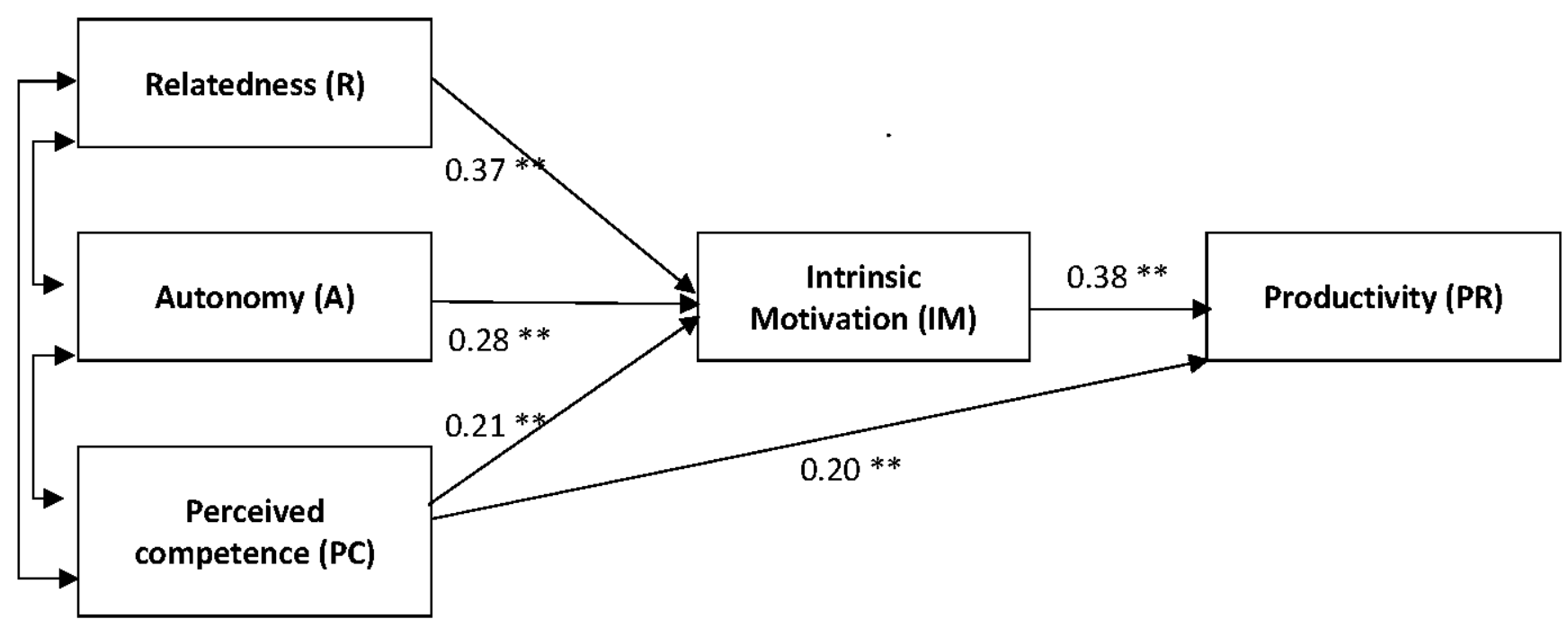

Figure 2. Standardised regression coefficients Model 3. ${ }^{* *} p<0.01$.

\section{Discussion and Conclusions}

\subsection{Discussion}

The results of this study show that enforced teleworking during the first lockdown has consequences for the motivation and productivity of employees in the higher education organisation. Compared to the pre-lockdown period, during the lockdown, employees experience a slight increase in autonomy and a slight increase in competence. While working from home, the average employee had the idea that they have a little more freedom in their work and were even a little more convinced than before that they can handle the challenges that their work offers. On the other hand, there is a clear decrease in perceived relatedness, intrinsic motivation, and productivity. Employees have less of a feeling of being part of a group, enjoy their work less, and have the idea that they do less work. 
Moreover, the results show that motivational processes can provide an explanation for the decrease in productivity of employees during the first lockdown. Since employees experience less relatedness at work, their intrinsic motivation decreases and, with it, their productivity at work. This decrease is somewhat moderated since employees experience a slight increase in autonomy and competence, which is positively related to intrinsic motivation and productivity. However, on balance the outcome is negative and intrinsic motivation and productivity decrease.

\subsubsection{Perceived Relatedness: Social Isolation}

An initial explanation for the decrease in productivity is related to the fact that contact with and between students, educational teams, and support is essential in (higher) education. Good contacts and human bonding between students, lecturers and staff ensure a safe climate in which learning is encouraged (Kappe 2017) and enhances organizational commitment (Nisha Chanana 2020; Galletta et al. 2011). In a sector in which social interactions between students, lecturers and staff together create education, employees were forced to master online working and remote teaching under high pressure and in a short period of time. However, due to the enormous challenge of putting digital education in order, the issue of reduced social contacts was neglected during the first lockdown (Toniolo-Barrios 2020; Brooks et al. 2020). The lower productivity found can be explained by a strong decrease in intrinsic motivation due to that lack of social relatedness. The certification organisation Great Place To Work (2020) therefore emphasises the importance of solidarity and personal attention for everyone in the current crisis (see Box 1).

Box 1. Practical implications.

What do the results mean for work organisation in practice?

Enforced working from home leads to less job satisfaction and therefore to less productivity.

Since the underlying reason is mainly a feeling of reduced relatedness, this is a key to improved work performance. Employer and employees can take initiatives to strengthen the perceived relatedness with colleagues.

The conviction of employees that they can cope with their work is also closely related to the intrinsic motivation and productivity of employees. Employers and employees could take initiatives to further strengthen the online work competencies of employees, also in the field of social relatedness. Since the expected increase in autonomy in a home working situation is not confirmed in this study, organisations are advised to exercise restraint when using instruments to monitor employees when working from home.

\subsubsection{Perceived Autonomy: Enforced Self-Determination}

Although before the COVID crisis working from home was mainly used to offer more highly qualified people more freedom to organise and perform their work for a limited number of hours or days a week (Felstead and Henseke 2017), this study shows that in a research group of predominantly higher educated people in a full-time telework situation only a very limited increase in autonomy is experienced. The paradoxical situation of enforced self-determination in the first lockdown turns out to be counterproductive for perceiving more autonomy, resulting in loss of intrinsic motivation. It seems that the optimism about autonomy in the home-working situation from previous studies must be qualified if there is an enforced nature. Autonomy in working from home is also limited for educators since class times are fixed, whether in school or online.

\subsubsection{Perceived Competence: Preference for Working Online}

Despite the greatly reduced intrinsic motivation of employees, there has been no greater drop in productivity. This can be explained by the third basic need of the selfdetermination theory: belief in one's own ability. The study found a slight increase in participants' sense of competence. As such, the prediction that employees during the first uncertain lockdown (in which the offering of facilities and support had yet to get underway and employees were more or less left to their own devices) experienced less confidence in 
themselves did not come true. The slight increase in perceived competences is probably due to a group of employees who indicated that they have a preference for working online. This group appears to be more productive than others (and perhaps better equipped with digital facilities) which has a mediating and moderating effect on the general decrease in productivity that is seen in people who do not share this preference. The employees with a preference for working online felt sufficiently skilled to perform online, with confidence in their own abilities. This may also explain why the number of stress-related complaints was not particularly high. The widely displayed and successful craftsmanship in the up-skilling from physical to online working is something to be proud of for professionals in higher education. In this light, the observed slight increase in confidence in one's own abilities is actually only modest. The unique achievement of switching from mainly face-to-face contact to fully online education and support within a few weeks should actually be reason for a greater sense of perceived competence.

Deci and Ryan's self-determination theory appears to be a useful model to monitor and explain the quality of employee performance in times of enforced working from home. An explanation for the decrease in intrinsic motivation can be found in the three independent variables (autonomy, competence, and relatedness) of the SDT model. The slight increase in the feeling of autonomy, lack of experience with online competences, and in particular the sudden loss of face-to-face contact do not seem like ideal conditions for job satisfaction. This may result in a decrease in intrinsic motivation of employees, with negative consequences for their performance at work. The self-determination theory of Deci and Ryan not only gives direction to how working is experienced in an enforced home working situation, but also offers tools for improvement. Due to the paradoxical relationship of self-determination in an enforced work situation, we prefer to focus on the two independent variables competence and relatedness. We learn from the group of employees with a preference for online working that having (a preference for) digital competences pays off and leads to better work performance when working from home. Compared to commonly heard tips such as online coffee breaks or informal walking appointments, the impact of systematic training in communication technology knowledge and skills seems more conducive to the perception of relatedness. A promising option could be the creation of a personal digital identity, supporting employees in establishing proactive and creative contact with students, colleagues and managers. In this way, professionals get a more sustainable instrument with which a fait accompli can be turned into an opportunity in a society in which more and more people will be teleworking.

\subsection{Conclusions}

The study has a solid theoretical basis, in which the relationships found between sources and consequences of intrinsic motivation are in line with Ryan and Deci's selfdetermination theory and have been demonstrated in numerous previous studies (see for example Ryan and Deci 2020; Guay et al. 2008). The study shows that the hypothesised model offers a valid framework for explaining motivational processes in the work situation, even in a practical situation with special circumstances.

The results of this study cannot, of course, be simply generalised. For example, employees' perception during the second lockdown that started in December 2021 may be entirely different. The question to be asked during the re-measurement scheduled for the spring of 2021 (one year after the first measurement) is therefore whether we will find comparable results or whether the relationships found have been strengthened or reduced. In this follow-up study, we will explicitly address the influence of employees' personal preference for working online or offline on their intrinsic motivation, productivity and stress-related complaints. In addition, it should also be noted that, while a crosssectional study does show relationships between variables, it cannot demonstrate causal relationships. Although subjective measurements using self-assessment questionnaires are a common means of measuring motivation concepts (Ziegler et al. 2007), it would be 
nice to also use behavioural indicators in a follow-up study to measure variables such as productivity and health issues.

Finally, the question is whether the same mechanisms exist within organisations and sectors with different ways of working and options for working from home. This is a particular sector in which contacts were normally on a face-to-face basis. The evidence from others sources is inconclusive. Research in the charitable sector by Schulpen LW and S (2020) indicates that the crisis actually strengthened motivation. A survey among home workers by Van Veldhoven and Gelder (2020) paints a diffuse picture, with a positive effect for some home workers and a negative effect on motivation and productivity for others. A follow-up study looking at the interplay between intrinsic motivation, relatedness, autonomy, and competence across a spectrum of sectors needs clarification.

Author Contributions: Conceptualization: J.R.R. and D.H.; methodology: D.H.; software: D.H.; validation: J.R.R. and D.H.; formal analysis: D.H.; investigation: J.R.R., D.H. and A.E.B.; resources: J.R.R. and D.H.; data curation: J.R.R. and D.H.; writing-original draft preparation: J.R.R. and D.H.; writing-review and editing: J.R.R., D.H., A.E.B. and J.W.; visualization: D.H.; supervision: J.R.R.; project administration: J.R.R.; All authors have read and agreed to the published version of the manuscript.

Funding: This research received no external funding.

Institutional Review Board Statement: Not application.

Informed Consent Statement: Informed consent was obtained from all subjects involved in the study.

Data Availability Statement: Not application.

Conflicts of Interest: The authors declare no conflict of interest.

\section{References}

Baane, Ruurd, Patrick Houtkamp, and Marcel Knotter. 2011. Het nieuwe werken ontrafeld: Over bricks, bytes \& behaviour. Journal of Social Intervention: Theory and Practice 20: 118.

Bae, Kwang Bin, David Lee, and Hosung Sohn. 2019. How to Increase Participation in Telework Programs in U.S. Federal Agencies: Examining the Effects of Being a Female Supervisor, Supportive Leadership, and Diversity Management. Public Personnel Management 48: 565-83. [CrossRef]

Bandura, Albert. 2012. On the Functional Properties of Perceived Self-Efficacy Revisited. Journal of Management 38: 9-44. [CrossRef]

Baruch, Yehuda. 2001. The status of research on teleworking and a agenda for future research. International Journal of Management Reviews 3: 113-29. [CrossRef]

Baumeister, Roy F., Jennifer D. Campbell, Joachim I. Krueger, and Kathleen D. Vohs. 2003. Does high self-esteem cause better performance, interpersonal success, happiness, or healthier lifestyles? Psychological Science in the Public Interest 4: 1-44. [CrossRef] [PubMed]

Bloom, Nicholas, James Liang, John Roberts, and Zhichun Jenny Ying. 2013. Does Working from Home Work? Evidence from a Chinese Experiment. Quarterly Journal of Economics 130: 165-218. [CrossRef]

Brooks, Samantha K., Rebecca K. Webster, Louise E. Smith, Lisa Woodland, Simon Wessely, Neil Greenberg, and Gideon James Rubin. 2020. The psychological impact of quarantine and how to reduce it: Rapid review of the evidence. Lancet 395: 912-20. [CrossRef]

Brynjolfsson, Erik, John J. Horton, Adam Ozimek, Daniel Rock, Garima Sharma, and Hong-Yi TuYe. 2020. COVID-19 and Remote Work: An Early Look at US Data. NBER Working Paper No. 27344 June 2020. Cambridge: National Bureau of Economic Research.

Dambrin, Claire. 2004. How does telework influence the manager-employee relationship? International Journal of Human Resources Development and Management 4: 358-75. [CrossRef]

Deci, Edward L., and Richard M. Ryan. 2012a. Self-determination theory. In Handbook of Theories of Social Psychology. Edited by Paul A. M. Van Lange, Arie W. Kruglanski and E. Tory Higgins. Newcastle: Sage Publications Ltd., pp. 416-36. [CrossRef]

Deci, Edward L., and Richard M. Ryan. 2012b. Motivation, personality, and development within embedded social contexts: An overview of self-determination theory. In The Oxford Handbook of Human Motivation. Edited by Richard M. Ryan. Oxford: Oxford University Press, pp. 85-107.

Delanoeije, Joni, and Marijke Verbruggen. 2020. Between-person and within-person effects of telework: A quasi-field experiment. European Journal of Work and Organizational Psychology 29: 795-808. [CrossRef]

Dery, Kristine, and Ella Hafermalz. 2016. Seeing is Belonging: Remote Working, Identify and Staying Connected. In The Impact of ICT on Work. Edited by Jungwoo Lee. New York: Springer, pp. 109-26. 
Errichiello, Luisa, and Tommasina Pianese. 2016. Organizational Control in the Context of Remote Work Arrangements: A Conceptual Framework. In Performance Measurement and Management Control: Contemporary Issues (Studies in Managerial and Financial Accounting, vol. 31). Edited by Marc J. Epstein, Frank Verbeeten and Sally K. Widener. Bingley: Emerald group Publishing, pp. 273-305.

Felstead, Alan, and Golo Henseke. 2017. Assessing the growth of remote working and its consequences for effort, well-being and work-life balance. New Technology, Work and Employment 32: 195-212. [CrossRef]

Gajendran, Ravi S., and David A. Harrison. 2007. The good, the bad, and the unknown about telecom-muting: Meta-analysis of psychological mediators and individual consequences. Journal of Applied Psychology 92: 1524-41. [CrossRef]

Gajendran, Ravi S., David A. Harrison, and Kelly Delaney-Klinger. 2014. Are Telecommuters Remotely Good Citizens? Unpacking Telecommuting's Effects on Performance Via I-Deals and Job Resources. Personnel Psychology 68: 353-93. [CrossRef]

Galletta, Maura, Igor Portoghese, and Adalgisa Battistelli. 2011. Intrinsic Motivation, Job Autonomy and Turnover Intention in the Italian Healthcare: The Mediating Role of Affective Commitment. Journal of Management Research 3: E3. [CrossRef]

Grant, Christine A., Louise M. Wallace, and Peter C. Spurgeon. 2013. An exploration of the psychological factors affecting remote e-worker's job effectiveness, well-being and work-life balance. Employee Relations 35: 527-46. [CrossRef]

Great Place To Work. 2020. Goed Werkgeverschap in Tijden Van Corona. Available online: https://info.greatplacetowork.nl/ coronacrisis (accessed on 4 May 2021).

Guay, Frédéric, Catherine F. Ratelle, and Julien Chanal. 2008. Optimal learning in optimal contexts: The role of self-determination in education. Canadian Psychology 49: 233-40. [CrossRef]

Hamersma, M., M. De Haas, and R. Faber. 2020. Thuiswerken en de Coronacrisis: Een Overzicht van Studies naar de Omvang, Beleving en Toekomstverwachting van Thuiswerken in Coronatijd. Den Haag: Kennisinstituut voor Mobiliteitsbeleid I KiM.

Hoornweg, Niels, Pascale Peters, and Beatrice Van der Heijden. 2016. Finding the Optimal Mix between Telework and Office Hours to Enhance Employee Productivity: A Study into the Relationship between Telework Intensity and Individual Productivity, with Mediation of Intrinsic Motivation and Moderation of Office Hours: New Ways of Working Practices. Advanced Series in Management 16: 1-28.

Kappe, F. Rutger. 2017. Studiesucces: Verbinden als Stap Voorwaarts. Inholland: Haarlem.

Klassen, Robert M., Nancy E. Perry, and Anne C. Frenzel. 2012. Teachers' relatedness with students: An underemphasized component of teachers' basic psychological needs. Journal of Educational Psychology 104: 150-65. [CrossRef]

Kline, Rex B. 2015. Principles and Practice of Structural Equation Modeling. New York: Guilford Publications.

Koppes, L. L. J., E. M. M. de Vroome, M. E. M. Mol, B. J. M. Janssen, and S. N. J. van den Bossche. 2011. De Nationale Enquête Arbeidsomstandigheden 2010. Methodologie En Globale Resultaten. Hoofddorp: TNO.

Kurland, Nancy B., and Cecily D. Cooper. 2002. Manager control and employee isolation in telecommuting environments. Journal of High Technology Management Research 13: 107-26. [CrossRef]

Legault, Lisa. 2020. Intrinsic and Extrinsic Motivation. In Encyclopedia of Personality and Individual Differences. Edited by V. Zeigler-Hill and T. K. Shackelford. Cham: Springer. [CrossRef]

Major, Debra A., Jennifer M. Verive, and Wendell Joice. 2008. Telework as a dependent care solution: Examining current practice to improve telework management strategies. Psychologist-Manager Journal 11: 65-91. [CrossRef]

Misbah, Zainun, Judith Gulikers, Wahyu Widhiarso, and Martin Mulder. 2021. Exploring connections between teacher interpersonal behaviour, student motivation and competency level in competence-based learning environments. Learning Environments Research 1-21. [CrossRef]

Reeve, Johnmarshall. 2002. Self-determination theory applied to educational settings. In Handbook of Self-Determination Research. Edited by Edward L. Deci and Richard M. Ryan. Rochester: University of Rochester Press, pp. 183-203.

Ryan, Richard M. 1982. Control and information in the intrapersonal sphere: An extension of cognitive evaluation theory. Journal of Personality and Social Psychology 43: 450-61. [CrossRef]

Ryan, Richard M., and Edward L. Deci. 2000. Self-determination theory and the facilitation of intrinsic motivation, social development, and wellbeing. American Psychologist 55: 68-78. [CrossRef]

Ryan, Richard M., and Edward L. Deci. 2020. Intrinsic and extrinsic motivation from a self-determination theory perspective: Definitions, theory, practices, and future directions. Contemporary Educational Psychology 61: 101860. [CrossRef]

Sanders, Stuart, and Joanna Karmowska. 2020. Voluntary flexible working arrangements and their effects on managers and employees. Harvard Deusto Business Research IX: 197-220.

Nisha Chanana, Sangeeta. 2020. Employee engagement practices during COVID-19 lockdown. Journal of Public Affairs 1: e2508.

Schulpen LW, van Kempen LA, and Kinsbergen S. 2020. Covid-19: De veerkracht van de Goededoelensector. Nijmegen: Department of Anthropology \& Development Studies-CAOS, Centraal Bureau Fondsenwerving (CBF), Radboud Universiteit.

Sewell, Graham, and Laurent Taskin. 2015. Out of Sight, Out of Mind in a New World of Work? Autonomy, Control, and Spatiotemporal Scaling in Telework. Organization Studies 36: 1507-29. [CrossRef]

Statistics Netherlands. 2020. Bijna 4 op de 10 Werkenden Werkten Vorig Jaar Thuis. Available online: https://www.cbs.nl/nl-nl/ nieuws/2020/15/bijna-4-op-de-10-werkenden-werkten-vorig-jaar-thuis (accessed on 6 April 2020).

Toniolo-Barrios, Mariana. 2020. Mindfulness and the Challenges of Working from Home in Times of Crisis. Bloomington: Business Horizons, Indiana University. 
Vallerand, Robert J. 1997. Toward a hierarchical model of intrinsic and extrinsic motivation. In Advances in Experimental Social Psychology. Edited by M. P. Zanna. Cambridge: Elsevier Academic Press, vol. 29, pp. 271-360.

Vansteenkiste, Maarten, Joke Simons, Willy Lens, Kennon M. Sheldon, and Edward L. Deci. 2004. Motivating Learning, Performance, and Persistence: The Synergistic Effects of Intrinsic Goal Contents and Autonomy-Supportive Contexts. Journal of Personality and Social Psychology 87: 246-260. [CrossRef]

van der Kleij, Rick, Merle Blok, Olav Aarts, Pepijn Vos, and Livia Weyers. 2013. Het nieuwe werken en kennisdelen: De rol van organisatie-identificatie en autonomie. Tijdschrift voor Arbeidsvraagstukken 2013: 63-82. [CrossRef]

Van Veldhoven, Marc, and Marco van Gelder. 2020. Ervaringen met thuiswerken tijdens COVID-19: Europees Vragenlijstonderzoek onder 5000 kenniswerkers Gedurende de Eerste Weken van de Lockdown. Tilburg: Rapportage Nederland, Universiteit Tilburg.

Wang, Wendy, Leslie Albert, and Qin Sun. 2020. Employee isolation and telecommuter organizational commitment. Employee Relations 42: 609-25. [CrossRef]

Ziegler, Matthias, Lothar Schmidt-Atzert, Markus Buhner, and Stefan Krumm. 2007. Fakability of different measurement methods for achievement motivation: Questionnaire, semi-projective, and objective. Psychology Science 49: 291-307. 